\title{
PENGARUH REKRUTMEN, FASILITAS OLAHRAGA, DAN PEMBERDAYAAN TERHADAP MOTIVASI SERTA DAMPAKNYA PADA PRESTASI ATLET DI PUSAT PEMBINAAN LATIHAN PELAJAR (PLPP) DAN PUSAT PEMBINAAN LATIHAN DAERAH (PPLD) ACEH
}

\author{
Rusdi $^{1}$, Damrus ${ }^{2}$ \\ Dosen Fakultas Ekonomi Universitas Teuku Umar \\ rusdi@utu.ac.id ${ }^{1}$ \\ damrus@utu.ac.id ${ }^{2}$
}

\begin{abstract}
This survey examines relationship between recruitment, sport facilities and empowerment through motivation toward athletes' prestations. The survey took 119 athletes as data whose included in Pusat Pembinaan Latihan Pelajar (PLPP) dan Pusat Pembinaan Latihan Daerah (PPLD) Aceh. This research used path analysis to analyze the data and finds that recruitment, sport facilities and empowerment have an impact to the motivation and athletes' prestations directly and indirectly. Through that condition indirectly all the exogenous factors have impact to athletes' prestations.
\end{abstract}

Key words : recruitment, sport facilities, empowerment, motivation, athletes' prestations

\begin{abstract}
ABSTRAK
Survey ini menjelaskan hubungan antara rekrutmen, fasilitas olahraga dan pemberdayaan melalui motivasi terhadap prestasi atlet. Survey ini mengambil 119 orang atlet sebagai sumberdata yang terlibat dalam Pusat Pembinaan Latihan Pelajar (PLPP) dan Pusat Pembinaan Latihan Daerah (PPLD) Aceh. Penelitian ini menggunakan model analisa jalur untuk menganalisa seluruh data yang telah dikumpulkan dan menemukan bahwa rekrutmen, fasilitas olahraga and pemberdayaan melalui motivasi terhadap prestasi atlet baik secara langsung maupun tak langsung. Sehingga seluruh variable eksogen secara tak langsung sebenarnya juga mempengaruhi prestasi atlet.
\end{abstract}

Kata kunci: rekrutmen, fasilitas olahraga pemberdayaan, motivasi, prestasi atlet. 


\section{PENDAHULUAN}

\subsection{Latar Belakang Penelitian}

Fenomena saat ini prestasi olahraga di negara Indonesia sedang menurun drastis dibandingkan sepuluh tahun yang lalu. Dulu tim bulutangkis kita merupakan tim yang sangat ditakuti apabila berhadapan untuk bertanding dan selalu diharapkan untuk dihindari, tapi sekarang malah pamornya sudah mulai meredup untuk berkiprah diajang internasional. Demikian juga kondisi olahraga di Aceh, jumlah perolehan medali, semakin menurun dari tahun ke tahun misalnya, pada pada Pekan Olahraga Nasional (PON) XVII 2008 di Kalimantan Timur peringkat Aceh berada di urutan 23 dengan perolehan medali 4 emas, 4 perak dan 10 perunggu, sedangkan PON XVIII 2012 di Riau perolehan medali berjumlah 3 emas 5 perak dan 18 perunggu berada di urutan 25 dari 33 provinsi yang mengikutinya. Motivasi atlet ini dapat dipengaruhi oleh beberapa faktor diantaranya adalah proses rekrutmen. Proses rekrutmen dalam menjaring atlet baru yang berkualitas merupakan prioritas pertama yang harus menjadi perhatian para pengambil keputusan dalam suatu organisasi dalam hal ini Dinas Pemuda dan Olahraga Aceh (Dispora Aceh).

Fasilitas yang dimiliki oleh Pemerintah Aceh dalam rangka meningkatkan prestasi atlet masih relatif kurang memadai. Hal ini dapat dilihat dari fasilitas yang digunakan para atlet dalam rangka meningkatkan prestasinya sebagaimana dijelaskan pada Tabel 1.1 berikut ini:

Tabel 1.1

Jumlah Fasilitas Olahraga

\begin{tabular}{|c|l|l|l|}
\hline No. & \multicolumn{1}{|c|}{ Cabang } & \multicolumn{1}{c|}{ Fasilitas } & \multicolumn{1}{c|}{ Keterangan } \\
\hline 1. & Sepakbola & Stadion Lhong Raya & Fasilitas pendukung kurang \\
\hline 2. & Taekwondo & Hall Serba Guna & Kurang memadai \\
\hline 3. & Kempo & Gedung Sendiri & Kurang memadai \\
\hline 4. & Atletik & Trek Atletik & Kurang memadai \\
\hline 5. & Anggar & Gedung & Kurang memadai \\
\hline 6. & Pencak Silat & Gedung & Kurang memadai \\
\hline 7. & Bulutangkis & Gedung & Kurang memadai \\
\hline 8. & Karate & Gedung & Kurang memadai \\
\hline 9. & Dayung & Sungai Lamnyong & Kurang memadai \\
\hline 10 & Panahan & Stadion & Kurang memadai \\
\hline 11. & Bola Volly & Stadion/Lap. Terbuka & Kurang memadai \\
\hline 12. & Bola Basket & Stadion/Lap. Terbuka & Kurang memadai \\
\hline
\end{tabular}

Sumber: Dispora Aceh, 2014

\section{TINJAUAN KEPUSTAKAAN}

Dalam mendapatkan hasil yang optimal dan terbaik bagi sebuah organisasi, maka pemberdayaan adalah sebuah cara yang cukup praktis dan produktif, maka dari itu, sebuah organisasi harus memiliki proses atau model yang jelas dalam melakukan pemberdayaan sumber dayanya. Model pemberdayaan yang dapat diterapkan dalam sebuah organisasi agar terjaminnya keberhasilan proses pemberdayaan dalam organisas, seperti ditunjukkan dalam gambar dibawah ini: 
Jurnal Bisnis dan Kajian Strategi Manajemen

Volume 3 Nomor 1, 2019

ISSN : 2614-2147

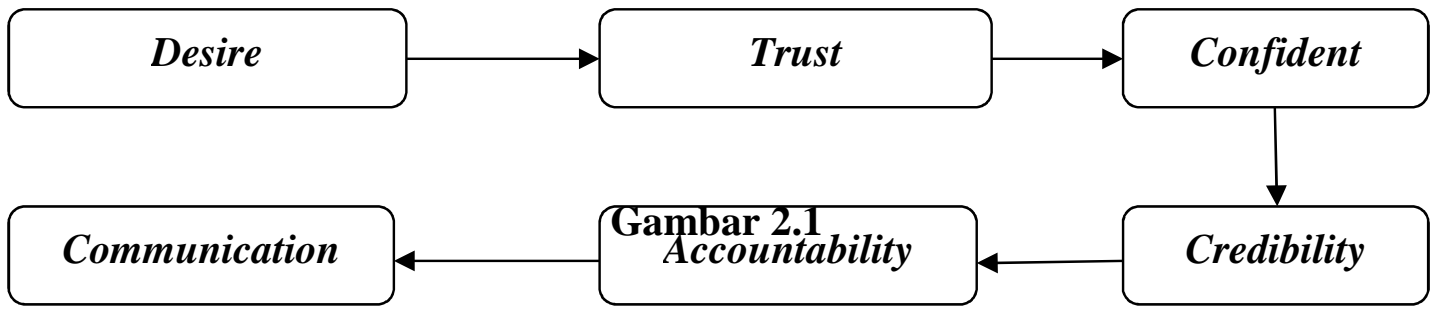

Model Empowerment (Pemberdayaan)

Berdasarkan di atas, maka dapat dijelaskan sebagai berikut:

Desire

Dalam tahap pertama dari empowerment adalah muncul keingingan (desire) dari pihak manajemen untuk mendelegasikan serta melibatkan pekerja.

Trust

Setelah adanya keingingan (desire), berikutnya adalah membangun kepercayaan

(trust) pihak manajemen dan pihak karyawan.

\section{Confident}

Setelah adanya kepercayaan antara manajemen dan pegawai, maka akan meimbulkan sikap rasa percaya diri karyawan karena telah adanya penghargaan atas kemampuan yang dimiliki oleh karyawan.

\section{Credibility}

Langkah selanjutnya adalah menjaga kredibilitas dengan cara mengembangkan lingkungan kerja dan iklim yang mendorong adanya kompetisi sehat agar tercipta organisasi dengan performance tinggi.

\section{Accountability}

Proses selanjutnya adala pertanggung-jawaban karyawan atas wewenang yang telah diberikan.

\section{Communication}

Proses terakhir adalah komunikasi terbuka untuk menciptakan saling pemahaman antar pihak karyawan terhadap pihak manajerial.

\subsection{Pengaruh Rekrutmen Terhadap Motivasi}

Menurut pendapat Simamora (2004:170) yang dikemukakan Apriani dan Ruzikna (2014: 5), bahwa "rekrutmen merupakan serangkaian aktivititas untuk mencari dan memikat pelamar kerja dengan motivasi, kemampuan, keahlian, dan pengetahuan". Dari pendapat di atas, dapat disimpulkan bahwa dalam proses rekrutmen pelamar kerja salah satunya dipengaruhi oleh motivasi. Dengan demikian, rekrutmen mempunyai hubungan dengan motivasi.

\subsubsection{Pengaruh Fasilitas Terhadap Motivasi}

Menurut teori yang dikemukakan oleh Frederick Hezberg (1966) yang dikutip oleh Riggio (2003) dengan Teori Model dan Faktor, bahwa faktor yang mempengaruhi kondisi pekerjaan seseorang antara lain adalah faktor pemeliharaan (maintenance factor) yang dikenal juga sebagai hygiene factor, antara lain; gaji, kondisi kerja fisik, kepastian pekerjaandan lain sebagainya. 


\section{Jurnal Bisnis dan Kajian Strategi Manajemen}

Volume 3 Nomor 1, 2019

ISSN : 2614-2147

Dari pendapat diatas, motivasi dipengaruhi oleh kondisi kerja fisik, dimana salah satunya adalah peralatan ataupun fasilitas. Dengan demikian dapat disimpulkan bahwa fasilitas berpengaruh terhadap motivasi.

\subsubsection{Pengaruh Pemberdayaan Terhadap Motivasi}

Menurut Suhermin (2012: 213) yang mengutip pendapat Luthan (2007)

menjelaskan tentang pemberdayaan yang diartikan sebagai sebuah pengakuan serta penggalian untuk tercapainya kepentingan bersama organisasi. Lebih jauh Malen dan Tandi (2006: 94-95) menjabarkan mengenai pemberdayaan sebagai hal yang harus dikaitkan dengan penggunaan rasional sehingga sumber daya yang ada dapat menentukan laju pertumbuhan dari produksi dan perbaikan tingkat hidup masyarakat. Dari pendapat di atas, dapat dikatakan bahwa pemberdayaan merupakan sebuah motivasi internal dari individu. Bila individu termotivasi maka akan menjadi pendorong untuk dapat melakukan hal tertentu. Hal ini disimpulkan juga bahwa pemberdayaan mempengaruhi motivasi.

\subsubsection{Pengaruh Rekrutmen Terhadap Prestasi Atlet}

Menurut Apriani (2014: 9) yang mengutip pendapat Siagian (2006:102) bahwa "Rekrutmen adalah proses mencari, menemukan dan menarik para pelamar yang kapabel untuk dipekerjakan dalam suatu organisasi”.

Berdasarkan pendapat di atas bahwa rekrutmen bertujuan mencari individu yang kapabel atau mempunyai kemampuan. Individu yang kapabel diharapkan akan menghasilkan kinerja yang tinggi sehingga mampu mencapai tujuan dari organisasi. Dengan demikian dapat disimpulkan bahwa rekrutmen mempunyai pengaruh terhadap kinerja.

\subsubsection{Pengaruh Fasilitas Tehadap Prestasi Atlet}

Menurut Erniati dan Sembiring (2012: 10) yang mengutip pendapat Moekijat (2001:155) dalam artikelnya, bahwa "secara sederhana yang dimaksud dengan fasilitas adalah suatu sarana fisik yang dapat memproses suatu masukan (input) menuju keluaran (output) yang diinginkan”.

Dari pendapat diatas, bahwa fasilitas dapat memproses suatu masukan dan menghasilkan output. Output yang dimaksud dalam konteks ini dapat dikatakan merupakan kinerja, sehingga dapat ditarik kesimpulan bahwa fasilitas mempunyai pengaruh pada kinerja.

\subsubsection{Pengaruh Pemberdayaan Terhadap Prestasi Atlet}

Menurut Isrorina dan Setyowati (2009: 2) yang mengutip pendapat Sudarusman (2004) tentang pemberdayaan (empowerment) yang diartikan sebagai proses yang mampu mendorong seorang individu dalam sebuah organisasi untuk mampu berinisiatif, mampu mengendalikan kewenangan dan secara bertanggung jawab menyelesaikan pekerjaan.

Dari pendapat di atas dapat disimpulkan bahwa dengan adanya pemberdayaan, maka individu terdorong dalam menyelesaikan pekerjaannya. Hasil dari pekerjaannya inilah yang dinamakan kinerja. Dengan demikian, pemberdayaaan berpengaruh terhadap prestasi. 
Volume 3 Nomor 1, 2019

ISSN : 2614-2147

\subsubsection{Pengaruh Motivasi Terhadap Prestasi Atlet}

Menurut Kurniawan et al. (2012: 6) yang mengutip pendapat Mathis et al. (2005) yang menyatakan banyak faktor yang dapat mempengaruhi kinerja individu, seperti kemampuan, motivasi, dukungan yang diterima, keberadaan pekerjaan yang mereka lakukan dan hubungan mereka dengan organisasi. Dari pendapat Mathis et al. (2005), menyatakan salah satu faktor yang mempengaruhi kinerja individu adalah motivasi. Dengan demikian motivasi mempunyai pengaruh terhadap kinerja. Berdasarkan uraian yang telah dikemukakan di atas, maka dapat digambarkan kerangka berpikir penelitian sebagai berikut:

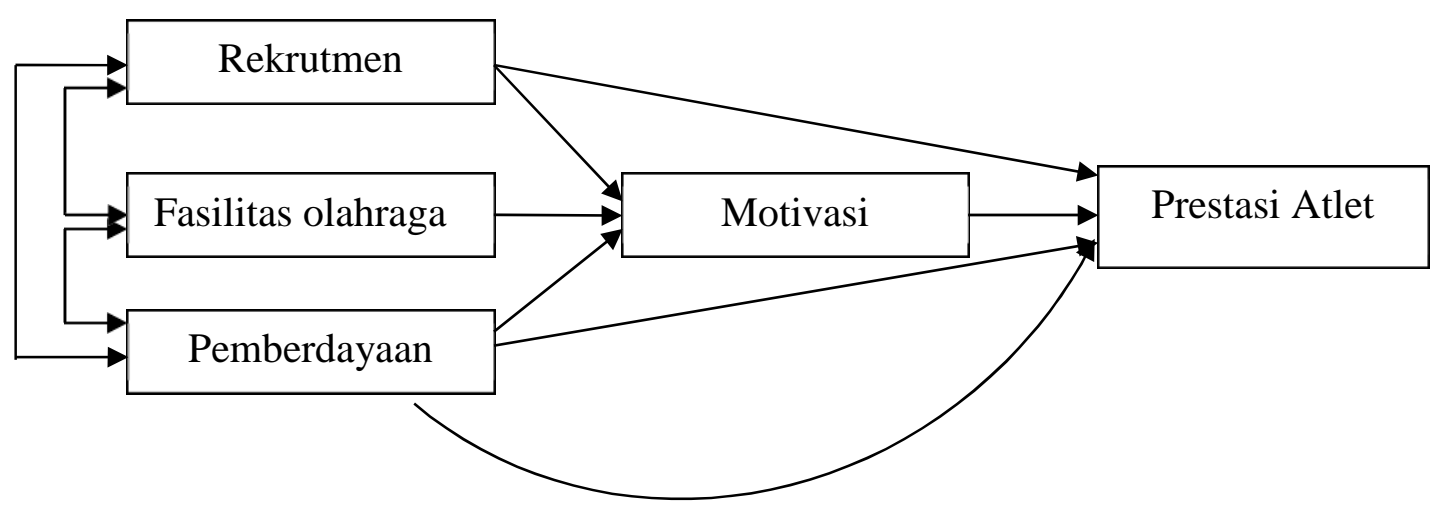

Gambar 2.2

Kerangka Berpikir Penelitian.

\section{Populasi dan Pengambilan Sampel}

Populasi dalam penelitian ini adalah seluruh atlet yang berasal di PPLP pada tahun 2013 yang berjumlah 119 orang, seperti yang disajikan pada tabel di bawah ini:

Jumlah Sampel Penelitian

\begin{tabular}{|c|l|c|c|c|}
\hline No. & Cabang Olahraga & $\begin{array}{c}\text { Jumlah } \\
\text { Atlet }\end{array}$ & $\mathbf{\%}$ & Keterangan \\
\hline 1. & Sepakbola & 32 & $26,9 \%$ & PPLD \\
\hline 2. & Taekwondo & 11 & $9,2 \%$ & PPLD \\
\hline 3. & Kempo & 5 & $4,2 \%$ & PPLD \\
\hline 4. & Atletik & 5 & $4,2 \%$ & PPLD \\
\hline 5. & Anggar & 7 & $5,9 \%$ & PPLD \\
\hline 6. & Pencak Silat & 12 & $10,1 \%$ & PPLD \\
\hline 7. & Bulutangkis & 5 & $4,2 \%$ & PPLD \\
\hline 8. & Karate & 11 & $9,2 \%$ & PPLD \\
\hline 9. & Dayung & 4 & $3,4 \%$ & PPLD \\
\hline 10 & Panahan & 4 & $3,4 \%$ & PPLD \\
\hline 11. & Angkat Berat & 11 & $9,2 \%$ & PPLD \\
\hline 12. & Bola Volly & 12 & $10,1 \%$ & PPLD \\
\hline Jumlah & $\mathbf{1 1 9}$ & $\mathbf{1 0 0} \%$ & \\
\hline
\end{tabular}


Volume 3 Nomor 1, 2019

ISSN : 2614-2147

\section{HASIL PENELITIAN}

\section{Uji Validitas dan Reliabilitas}

Indikator yang digunakan untuk pengujian validitas adalah membandingkan Nilai KMO-MSA and Bartlett's Test yang dihasilkan dengan syarat > 0,05 dan melihat apakah butir pertanyaan telah membentuk dalam satu komponen. Hasil pengujian validitas, semua indikator pengukuran variabel dinyatakan valid. Pengukuran reliabilitas dilakukan dengan menggunakan indikator cronbach alpha yang dinyatakan valid apabila nilai cronbach alpha minimal 0,6.

\section{Hasil Pengujian Reliabilitas}

\begin{tabular}{|c|c|c|c|c|}
\hline Variabel & $\begin{array}{c}\text { Cronbach's } \\
\text { Alpha }\end{array}$ & $\begin{array}{c}\mathrm{N} \text { of } \\
\text { Items }\end{array}$ & Syarat & Keterangan \\
\hline Prestasi atlet $(\mathrm{Z})$ & 0,806 & 3 & 0,6 & Handal \\
\hline Motivasi $(\mathrm{Y})$ & 0,904 & 5 & 0,6 & Handal \\
\hline Rekrutmen $\left(\mathrm{X}_{1}\right)$ & 0,744 & 4 & 0,6 & Handal \\
\hline Fasilitas $\left(\mathrm{X}_{2}\right)$ & 0,862 & 5 & 0,6 & Handal \\
\hline Pemberdayaan $\left(\mathrm{X}_{3}\right)$ & 0,900 & 4 & 0,6 & Handal \\
\hline
\end{tabular}

Sumber: Data Primer, 2014 (diolah)

\section{Pengujian Hipotesis}

Hasil uji hipotesis penelitian dapat dilihat pada table di bawah ini:

\begin{tabular}{|c|c|c|l|}
\hline Eksogen & Endogen & $\begin{array}{c}\text { t hitung: } \\
\text { t table } \\
\mathbf{( 1 , 6 5 8 3 3 )}\end{array}$ & Simpulan \\
\hline Rekrutmen & Motivasi & 2,794 & Hipotesis diterima \\
\hline Fasilitas & Motivasi & 2,248 & Hipotesis diterima \\
\hline Pemberdayaan & Motivasi & 3,127 & Hipotesis diterima \\
\hline Rekrutmen & Prestasi Atlet & 2,211 & Hipotesis diterima \\
\hline Fasilitas & Prestasi Atlet & 2,784 & Hipotesis diterima \\
\hline Pemberdayaan & Prestasi Atlet & 2,347 & Hipotesis diterima \\
\hline
\end{tabular}

Hasil pengujian hipotesis tersebut membentuk pengaruh langsung dan tak langsung antar variable eksogen dan endogen yang diteliti menjadi berikut:

Tabel 4.36

Pengaruh Langsung, Pengaruh Tidak Langsung dan Total Pengaruh

\begin{tabular}{|c|c|c|c|}
\hline Pengaruh Variabel & Langsung & Tidak Langsung Melalui Y & Total \\
\hline$X_{1} \rightarrow Y$ & 0,237 & - & 0,237 \\
\hline$X_{2} \rightarrow Y$ & 0,194 & - & 0,194 \\
\hline$X_{3} \rightarrow Y$ & 0,266 & - & 0,266 \\
\hline$X_{1} \rightarrow Z$ & 0,190 & - & 0,190 \\
\hline$X_{2} \rightarrow Z$ & 0,186 & - & 0,186 \\
\hline$X_{3} \rightarrow Z$ & 0,235 & - & 0,235 \\
\hline$Y \rightarrow Z$ & 0,209 & - & 0,209 \\
\hline$X_{1} \rightarrow Y \rightarrow Z$ & 0,237 & 0,050 & 0,287 \\
\hline
\end{tabular}


Jurnal Bisnis dan Kajian Strategi Manajemen

Volume 3 Nomor 1, 2019

ISSN : 2614-2147

\begin{tabular}{|c|c|c|c|}
\hline $\mathrm{X}_{2} \rightarrow \mathrm{Y} \rightarrow \mathrm{Z}$ & 0,194 & 0,041 & 0.235 \\
\hline $\mathrm{X}_{3} \rightarrow \mathrm{Y} \rightarrow \mathrm{Z}$ & 0,266 & 0,056 & 0.322 \\
\hline
\end{tabular}

Sumber: Data Primer 2014, (diolah)

Secara keseluruhan hubungan antara variable eksogen dan endogen baik secara langsung maupun tidak langsung dapat digambarkan sebagai berikut:

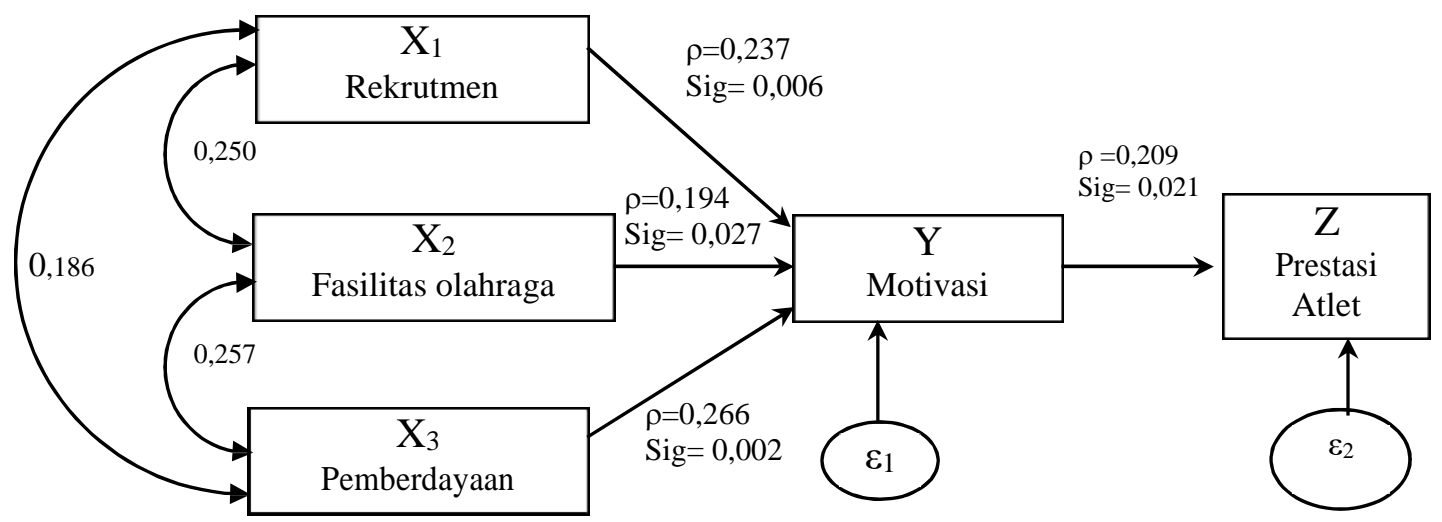

Berdasarkan di atas, maka dilakukan perhitungan untuk mengetahui pengaruh tidak langsung variabel eksogen terhadap variabel endogen melalui variabel intervening sebagai berikut:

a. Pengaruh tidak langsung variabel rekrutmen terhadap prestasi atlet melalui motivasi adalah:

$$
\begin{aligned}
\text { Inderect Effect } \mathrm{X}_{1} \rightarrow \mathrm{Y} \rightarrow & \mathrm{Z}=\rho_{1} \mathrm{YX}_{1} \mathrm{X} \rho_{5} \mathrm{ZY} \\
& =0,237 \times 0,209 \\
& =0,050
\end{aligned}
$$

b. Pengaruh tidak langsung variabel fasilitas olahraga terhadap prestasi atlet melalui motivasi adalah adalah:

Inderect Effect $\mathrm{X}_{2} \rightarrow \mathrm{Y} \rightarrow \mathrm{Z}=\rho_{2} \mathrm{YX}_{2} \mathrm{X} \rho_{5} \mathrm{ZY}$

$$
\begin{aligned}
& =0,194 \times 0,209 \\
& =0,041
\end{aligned}
$$

c. Pengaruh tidak langsung pemberdayaan terhadap prestasi atlet melalui motivasi adalah:

$$
\begin{aligned}
\text { Inderect Effect } \mathrm{X}_{3} \rightarrow \mathrm{Y} \rightarrow & \mathrm{Z} \\
& =\rho_{3} \mathrm{YX}_{3} \mathrm{X} \rho_{5} \mathrm{ZY} \\
& =0,266 \times 0,056 .
\end{aligned}
$$

a. Rekrutmen terhadap prestasi atlet secara langsung sebesar 0,190 atau lebih besar dari pengaruh tidak langsung rekrutmen terhadap prestasi atlet melalui motivasi sebesar 0,050 $(0,190>0,050)$.

b. Fasilitas olahraga terhadap prestasi atlet secara langsung sebesar 0,186 atau lebih besar dari pengaruh tidak langsung fasilitas olahraga terhadap prestasi atlet melalui motivasi sebesar $0,041(0,186>0,042)$.

c. Pemberdayaan terhadap prestasi atlet secara langsung sebesar 0,235 atau lebih besar dari pengaruh tidak langsung pemberdayaan terhadap prestasi atlet melalui motivasi sebesar 0,0,056 $(0,235>0,056)$. 


\section{Jurnal Bisnis dan Kajian Strategi Manajemen}

Volume 3 Nomor 1, 2019

ISSN : 2614-2147

Berdasarkan data-data pada tabel di atas, maka diagram lengkap seperti ditunjukkan pada gambar di bawah ini:

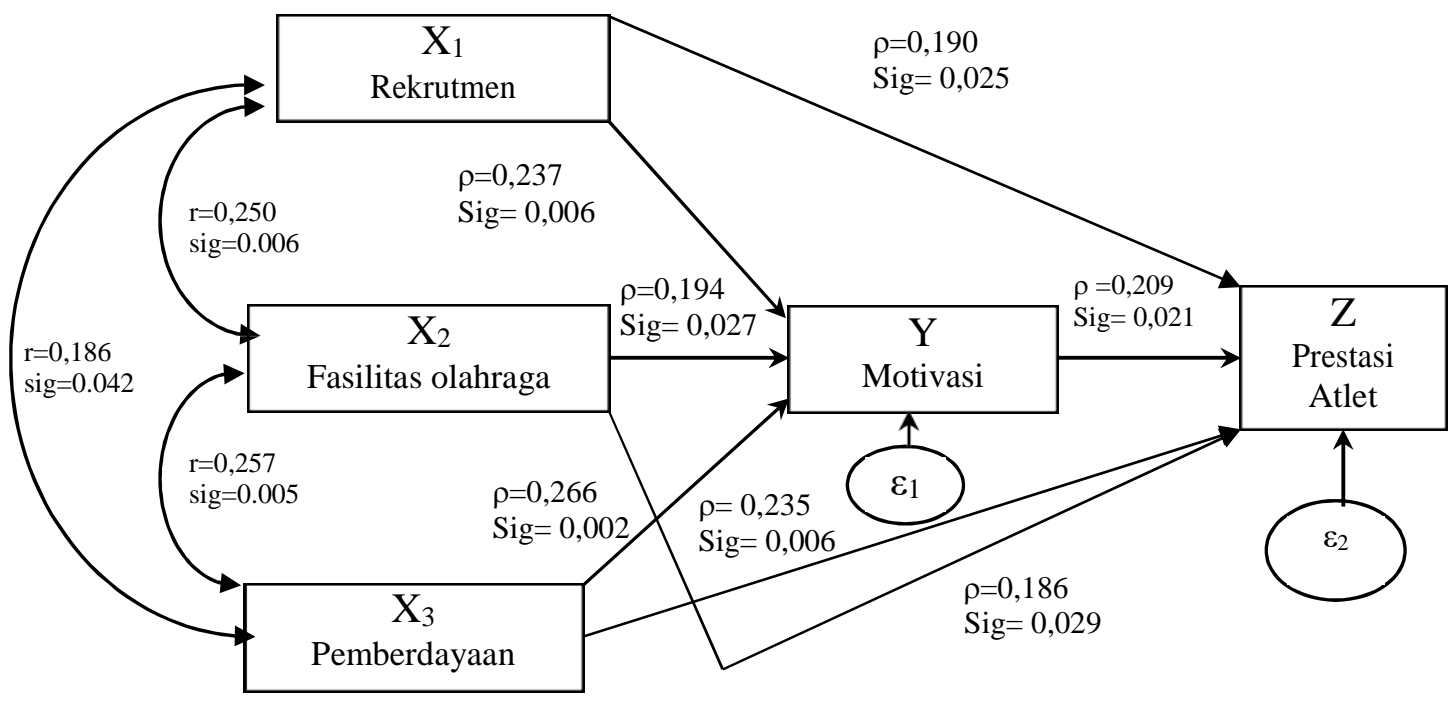

\section{Simpulan}

1. Pengaruh Rekrutmen, Fasilitas Olahraga dan Pemberdayaan terhadap Motivasi di Pusat Pembinaan Latihan Pelajar (PLPP) dan Pusat Pembinaan Latihan Daerah (PPLD) Aceh. Dari hasil penelitian yang dilakukan mengenai pengaruh variabel rekrutmen terhadap motivasi didapat hasil dengan pengaruh yang signifikan, baik secara parsial maupun simultan.

2. Pengaruh Rekrutmen, Fasilitas Olahraga dan Pemberdayaan terhadap Prestasi Atlet di Pusat Pembinaan Latihan Pelajar (PLPP) dan Pusat Pembinaan Latihan Daerah (PPLD) Aceh. Hasil dari penelitian mengenai pengaruh rekrutmen terhadap prestasi atlet di Pusat Pembinaan Latihan Pelajar (PLPP) dan Pusat Pembinaan Latihan Daerah (PPLD) Aceh dengan hasil menunjukkan pengaruh yang signifikan baik secara simultan maupun parsial telah mendukung teori yang dikemukakan oleh Robbins (1998).

3. Pengaruh Motivasi Terhadap Prestasi Atlet di Pusat Pembinaan Latihan Pelajar (PLPP) dan Pusat Pembinaan Latihan Daerah (PPLD) Aceh. Hasil dari penelitian mengenai pengaruh motivasi terhadap prestasi atlet di Pusat Pembinaan Latihan Pelajar (PLPP) dan Pusat Pembinaan Latihan Daerah (PPLD) Aceh dengan hasil yang menunjukkan pengaruh yang signifikan baik secara simultan maupun parsial telah mendukung teori yang dikemukakan oleh Timple bahwa faktorfaktor kinerja terdiri dari faktor internal dan eksternal. Faktor-faktor eksternal yaitu faktor-faktor yang mempengaruhi kinerja seseorang yang berasal dari lingkungan kerja organisasi.

4. Pengaruh Rekrutmen, Fasilitas Olahraga dan Pemberdayaan Terhadap Prestasi Atlet Pada Pusat Pembinaan Latihan Pelajar (PLPP) dan Pusat Pembinaan Latihan Daerah (PPLD) Aceh Melalui Motivasi. 


\section{Jurnal Bisnis dan Kajian Strategi Manajemen}

Volume 3 Nomor 1, 2019

ISSN : 2614-2147

\section{DAFTAR KEPUSTAKAAN}

Andrizul dan Yoserizal (2013),'Rekrutmen dan Penempatan Pegawai”, Jurnal Kebijakan Publik, Vol. 4, No.1,1-12.

Apriani. dan Ruzikna.(2014), "Pengaruh Pelaksanaan Rekrutmen Terhadap Kinerja Karyawan PT Riau Jaya Cemerlang Pekanbaru”, Jom Fisip, Vol.1, No. 2: 1-15.

Arifiyani, Hesti Arlich dan Sukirno (2012),"Pengaruh Pengendalian Intern, Kepatuhan Dan Kompensasi Manajemen Terhadap Perilaku Etis Karyawan (Studi Kasus PT Adi Satria Abadi Yogyakarta)", Jurnal Nominal, Vol. I, No. I: 1-17.

Atman (2014), "Pengaruh Kompensasi, Motivasi Kerja, Kepuasan Kerja Dan Komitmen Organisasi Terhadap Kinerja Pegawai Pada Kantor Wilayah Badan Pertanahan Nasional (BPN) Provinsi Sumatera Barat". eJournal, Vol. 4, No. 2: 1-13.

Bellionardi, Alpius Rama Kusuma. Dan Pujiarti, Emiliana Sri. (2013),"Model Analisis Perekrutan Dan Seleksi Karyawan Di PT. Semarang Autocomp Manufacturing Indonesia (SAMI)", Jurnal Ilmiah Dinamika Ekonomi dan Bisnis, Vol. 1, No. 1: $42-55$.

Ermiati, Cut dan Sembiring, Teridah. (2012), "Pengaruh Fasilitas Dan Pengembangan Sumber Daya Manusia Terhadap Produktivitas Kerja Karyawan Studi Kasus PTPN II Kebun Sampali Medan”, e-Journal, Vol. XX: 8-19.

Fakhrizal, Nuzul., Yunus, Mukhlis.dan Amri. (2012), “ Pengaruh Komitmen Individu, Organisasi Dan Gaya Kepemimpinan Terhadap Kinerja Pegawai Serta Dampaknya Pada Kinerja Dinas Pengelolaan Keuangan Dan kekayaan Aceh”. Jurnal Manajemen Pascasarjana Universitas Syiah Kuala, Vol. 2, No. 1: 68 -84.

Gunawan, Ketut. (2009), “Analisis Faktor Kinerja Organisasi Lembaga Perkreditan Desa di Bali (Suatu Pendekatan Perspektif Balanced Scorecard), Jurnal Manajemen Dan Kewirausahaan, Vol. 11, No. 2: 172-182.

Hariyanti dan Primawestri, Inten. (2011), "Pengaruh Komunikasi Dan Motivasi Kerja Terhadap Kinerja Perawat Dengan Komitmen Organisasi Sebagai Variabel Moderating”. e-Journal, Vol. 20, No. 22: 1-15.

Hasibuan, Malayu S P. (2006), Manajemen Sumber Daya Manusia, Jakarta Bumi Aksara.

PT. Bumi Aksara.

Isrorina dan Setyowati, Widhy. (200), "Pengaruh Pemberdayaan Pegawai Dan Karakteristik Pekerjaan Terhadap Kinerja Pegawai Dengan Mediasi Iklim Organisasi Pada Sekretariat Daerah Kabupaten Pekalongan", TEMA, Vol. 6, Edisi 1: 19-31.

Kurniawan, Dedi., Lubis, A. Rahman., dan Adam, Muhammad. (2012), "Pengaruh Budaya Kerja Dan Motivasi 


\section{Jurnal Bisnis dan Kajian Strategi Manajemen}

Volume 3 Nomor 1, 2019

ISSN : 2614-2147

Kerja Terhadap Kinerja Karyawan International Federation Red Cross (IFRC) Banda Aceh”. Jurnal Manajemen,Vol. 1, No. 1: 1-15.

Luthans, Fred. (2006), Perilaku Organisasi. Alih Bahasa Vivin Andika Yuwono, Yogyakarta: Andi Offset.

Maiyanti, Sri Indra., Dwipurwani, Oki., dan Yuliana, Ratu. (2012). "Analisis Prestasi Atlet Olah Raga Taekwondo Menggunakan Analisis Jalur (Studi Kasus Atlet Taekwondo-In di Karigamas Sport Club-Palembang), Jurnal Penelitian Sains, No.15 Vol. 1: 1-5.

Malen, Petrus Mangun. dan Tandi, Ismail. (2006), "Pemberdayaan Sumberdaya Manusia Pada PT. Nittoh Malino Teh Kelurahaan Bulutana, Kecamatan Tinggi Moncong, Kabupaten Gowa, Jurnal Agrisistem, Vol 2, No. 2 :93-107.

Mangkunegara, Anwar Prabu. (2001), Manajemen Sumber Daya Manusia Perusahaan. Bandung; PT. Remaja Rosdakarya.

Marzaweny, Diskha., Hadiwidjojo, Djumilah., dan Chandra, Teddy. (2012), “Analisis Kepuasan Pasien sebagai Mediasi Pengaruh Kualitas Pelayanan Kesehatan terhadap Citra Rumah Sakit Umum Daerah (RSUD) Arifin Achmad Pekanbaru”. Jurnal Aplikasi Manajemen, Vol. 10, No. 3 : 564-573.

Nasril, Ali., Chan, Syafrizal., dan Yuhelmi. (2013),’Pengaruh Motivasi, Kepuasan Kerja Dan Komitmen Organisasi Terhadap Kinerja Pegawai Pada Kantor Camat Di Kabupaten Pesisir Selatan", e-Journal, Vol. 3 No. 2: 1-13.

Neljon, Anes Rafika., Kamela, Ice., dan Dharma, Surya. (2014), "Pengaruh Motivasi Kerja Dan Lingkungan Kerja Terhadap Kinerja Pegawai (Studi Pada Kantor Camat Talawi Kota Sawahlunto)", e-Journal, No. 4, Vol. 2: 1-15.

Tika, Pabundu. (2008), “Budaya Organisasi dan Peningkatan Kinerja Perusahaan”. Jakarta: Bumi Aksara.

Putri, A.A Mega Rosa Arini. (2013), "Pengaruh Gaya Kepemimpinan, Budaya Organisasi dan Kompensasi Finansial Terhadap Kepuasan Kerja Karyawan Pada PT. Dunia Garmen Internasional di Denpasar", e-Journal, Vol. 3, No. 1: 183-204.

Riggio, R. E. (2003), Introduction to industrial/organizational Psychology, Fourth Edition. New Jersey, NJ:Prentice Hall.

Samsudin, Sadili. (2006), Manajemen Sumber Daya Manusia. Bandung: PT. Pustaka Setia. . (2010), Manajemen Sumber Daya Manusia, Cetakan ke 3. Bandung: CV Pustaka Setia.

Sudarusman, Eka (2004), "Pemberdayaan: Sebuah Usaha Memotivasi Karyawan", Fokus Ekonomi, Vol. 3, No.2.

Suhermin. (2012),'Pemberdayaan Kerja Profesional Sebagai Mediasi Dukungan Organisasi Dan Pertukaran Pemimpin-Anggota (LMX) Terhadap Komitmen Organisasional", Ekuitas: Jurnal Ekonomi dan Keuangan, Vol. 16, No. 2: 209-229. 


\section{Jurnal Bisnis dan Kajian Strategi Manajemen}

Volume 3 Nomor 1, 2019

ISSN : 2614-2147

Sutrisno, Edy. (2009), Manajemen Sumber Daya Manusia. Edisi Pertama. Cetakan Pertama. Jakarta: Kencana.

Suwatno dan Donni Juni Priansa.(2011), Manajemen SDM dalam Organisasi Publik dan Bisnis, Cetakan Kedua, Bandung: Alfabeta.

Tielung, Jaclyen (2013),"Pemberdayaan Karyawan, Motivasi Dan Komitmen Organisasi Terhadap Kinerja Karyawan Pada PT. PLN (Persero) Wilayah VII Manado”, Jurnal EMBA, Vol.1,No.4: 1799-1808.

Utomo, Sulistyo Budi. (2010),’Pengaruh Motivasi Dan Kepuasan Kerja Terhadap Kinerja Karyawan CV. Berkat Cipta Karya Nusantara Surabaya”, Jurnal Akuntansi, Manajemen Bisnis, (JAMBSP), Vol. 6. No. 3: 376-393.

Widayanti (2007), "Hubungan Pemberdayaan Pegawai dengan Peningkatan Produktivitas Pegawai (Studi Kasus pada Bagian Fiber dan Radio Access Maintenance PT. Telekomunikasi Bandung)”, Jurnal Ilmu Administrasi, Vol. IV, No. 3: 233-254.

Wulandani, Putri., Darmayanti, R, Yeasy., dan Rifa, Dandes. (2014), "Pengaruh Locus Of Control Terhadap Prestasi Kerja Auditor Dengan Gaya Kepemimpinan Situasional sebagai Variabel Moderating", e-Journal, Vol. 4. No. 1: 1-14. 